\title{
Measurement of exhaled alveolar nitrogen oxide in patients with lung cancer: a friend from the past still precious today
}

\author{
Anastasios Kallianos' \\ Sotirios Tsimpoukis ${ }^{2}$ \\ Paul Zarogoulidis ${ }^{3}$ \\ Kaid Darwiche 4 \\ Andriani Charpidou ${ }^{2}$ \\ Ilias Tsioulis ${ }^{3}$ \\ Georgia Trakada ${ }^{5}$ \\ Konstantinos Porpodis ${ }^{3}$ \\ Dionysios Spyratos 3 \\ Athanasios Panoutsopoulos 5 \\ Lemonia Veletza $^{5}$ \\ Konstantinos Kostopoulos 5 \\ Charalampos Kostopoulos ${ }^{4}$ \\ Ilias Karapantzos ${ }^{6}$ \\ Kosmas Tsakiridis ${ }^{7}$ \\ Wolfgang Hohenforst- \\ Schmidt ${ }^{8}$ \\ Konstantinos Zarogoulidis ${ }^{3}$ \\ Aggeliki Rapti' \\ Konstantinos Syrigos ${ }^{2}$ \\ 'Second Pulmonary Clinic, Sotiria Hospital, \\ ${ }^{2}$ Oncology Unit, Sotiria Hospital, Athens, \\ Greece; ${ }^{3}$ Oncology Unit, G Papanikolaou \\ General Hospital, Thessaloniki, Greece; \\ ${ }^{4}$ Interventional Unit, Ruhrland Clinic, \\ Essen, Germany; ${ }^{5}$ Pulmonary Laboratory, \\ Alexandra Hospital, Athens, Greece; 'Ear, \\ Nose, and Throat Department, Saint \\ Luke Private Hospital, ${ }^{7}$ Cardiothoracic \\ Department, Saint Luke Private Hospital, \\ Thessaloniki, Greece; ${ }^{8}$ II Medical Clinic, \\ Hospital of Coburg, Coburg, Germany
}

Correspondence: Paul Zarogoulidis Oncology Unit, Pulmonary Department, G Papanikolaou General Hospital, Aristotle University of Thessaloniki, Thessaloniki, 57010 Greece

Tel +306977271974

Fax +30 23I 992433

Email pzarog@hotmail.com
This article was published in the following Dove Press journal:

OncoTargets and Therapy

28 May 2013

Number of times this article has been viewed

\begin{abstract}
Nitric oxide (NO) is a marker of airway inflammation and indirectly a general indicator of inflammation and oxidative stress. NO is a contributing factor in lung cancer at an early stage and also after chemotherapy treatment of lung cancer. We studied whether exhaled NO levels were altered by three cycles of chemotherapy at diagnosis and after chemotherapy, and whether, directly or indirectly, these changes were related to the course of disease. Also, a correlation of NO levels with other markers of inflammation was performed. We studied 42 patients diagnosed early: 26 men and 16 women with lung cancer. We analyzed blood tests for control of inflammatory markers, functional pulmonary tests, and alveolar exhaled NO. We recorded a decrease in exhaled NO after three cycles of chemotherapy in all patients, regardless of histological type and stage: there were 42 patients with mean $9.8 \mathrm{NO}$ after three cycles (average 7.7). Also, a strong correlation appeared between NO measurements before and after chemotherapy and C-reactive protein $(P<0.05, r=0.42$, before $)$ and $(P<0.045, r=0.64$, after). NO alveolar measurement as an indicator of airway inflammation indicates response to chemotherapy in lung cancer. Also, the inflammatory process in lung cancer was confirmed and indicated response to chemotherapy through an index that is sensitive to inflammatory disease of the airways.
\end{abstract}

Keywords: nitric oxide, lung cancer, inflammation

\section{Introduction}

The lung is currently the most common origin of cancer tumors in the male European population (in the US, it comes after the prostate, while in Japan it comes after the digestive tract in men). A rate of $30 \%$ of all cancer-related deaths is attributed to lung cancer, as it presents high mortality. Lung cancer in the female population is currently found in fifth position worldwide and is increasing progressively. ${ }^{1}$

In fact, all lung cancers originate from epithelial tissue. There are various subtypes of bronchogenic carcinoma, with the most common being epidermoid carcinoma, adenocarcinoma, microcellular carcinoma, and large-cell carcinoma. These subtypes are reported in $99 \%$ of all histologically confirmed lung cancers. Non-small-cell lung cancer accounts for $80 \%$ of lung neoplasias. During first diagnosis, a small proportion of patients have limited disease (stages I and II), while most of them are diagnosed with locally advanced (stage III) and metastatic disease (stage IV), each with a different clinical course and different overall survival. ${ }^{2,3}$

During the last few years, several biological agents have been implicated in the pathogenetic mechanisms of cancer, mainly cytokines. It seems that cytokines play an important role in the growth of cancer cells and their ability to metastasize 
to remote tissues and form colonies. ${ }^{4-6}$ An inflammation marker is the measurement of exhaled nitric oxide. NO is produced in small quantities by epithelial and endothelial cells, but inflammatory cells contribute to the increase of NO levels, thus explaining the observed correlation between NO levels and eosinophilic inflammation. ${ }^{7-9}$ Exhaled NO is a noninvasive marker of airway inflammation. Some studies in progress are investigating how exhaled NO can play the role of a predictive factor and be correlated with other inflammatory diseases of the lung besides asthma. It has been observed that NO levels are high in the exhaled air of patients with bronchial asthma, whereas they are significantly lower in patients who receive treatment with inhaled steroids. ${ }^{10}$ It has also been found that although increased NO production in some cases enhances the airway inflammation induced by oxidative mechanisms, it can also at the same time have protective properties against cytotoxicity that is caused by the inflammation. ${ }^{11,12}$ In a humid environment like the inner surface of the airways, the production of NO may be expressed with the formation of stable end products of its metabolism, such as nitrates $\left(\mathrm{NO}_{3}\right)$ and nitrites $\left(\mathrm{NO}_{2}\right) \cdot{ }^{13}$

Oxidative stress, which is defined as an increased exposure to oxidative agents and/or low antioxidant activity, is involved in airway inflammatory diseases. The $\mathrm{O}_{2}$ and NO combination leads to the formation of peroxinitrate $\left(\mathrm{ONOO}^{-}\right)$, which is a particularly active molecule capable of damaging the bronchial epithelium. $\mathrm{O}_{2}$ is rapidly metabolized into hydrogen peroxide $\left(\mathrm{H}_{2} \mathrm{O}_{2}\right)$, which is diffused within the airways and evaporates in the exhaled air. $\mathrm{H}_{2} \mathrm{O}_{2}$ is increased in exhaled air condensate in patients with bronchial asthma and can be used as a noninvasive airway-inflammation marker. Exhaled NO has been proposed as an airway-inflammation marker. NO levels should normally be increased in the context of all airway inflammatory diseases. However, in patients with cystic fibrosis, NO levels were found to be normal or decreased compared to those of healthy subjects, while in patients with bronchiectasis no increased NO levels were found. ${ }^{14,15}$ Furthermore, more recent observations, such as in Horváth et al, revealed that there is no correlation between $\mathrm{NO}$ concentration in exhaled air and $\mathrm{H}_{2} \mathrm{O}_{2}$ in exhaled air condensate of asthma patients, mainly in those with an unstable clinical course. ${ }^{16,17}$ It is known that NO is an unstable volatile molecule that rapidly transforms into nonvolatile nitrates $\left(\mathrm{NO}_{3}^{-}\right)$and nitrites $\left(\mathrm{NO}_{2}^{-}\right)$, and this reaction is influenced by airway inflammation. ${ }^{18,19}$ Thus, the hypothesis was formulated that the measurement of stable end products of NO metabolism, such as nitrates and nitrites, is a more reliable way of expressing airway inflammation in conditions such as cystic fibrosis. ${ }^{20,21}$

The determination of nitrates in exhaled air condensate is performed through a chromatography method based on the Griess reaction. More specifically, $100 \mu \mathrm{L}$ of condensate are mixed with $100 \mu \mathrm{L}$ of Griess reagent ( $N$-[1-naphthyl] ethylenediamine dihydrochloride $0.1 \%$, sulfanilamide $0.1 \%$, $\mathrm{H}_{3} \mathrm{PO}_{4} 3 \%$ ). Then the absorption of the colored product of the reaction is measured with a photometer at $570 \mathrm{~nm}$. Nightingale et $\mathrm{al}^{22}$ measured the nitrates by means of a fluorometric method that was described by Misko et $\mathrm{al}^{23}$ and is more sensitive than the Griess assay. In a recent study, exhaled air condensate was measured for the total of nitrates and nitrites, ie, the total of NO metabolism end products. Therefore, the nitrates were enzymatically transformed into nitrates under the influence of nitrate reductase, and then total nitrates (reduced nitrates + nitrites) were measured with the Griess assay. ${ }^{23,24}$

We studied the change in exhaled NO levels after the onset of chemotherapy compared to the levels at diagnosis, and whether they were directly correlated to the course of the disease, as independent predictive factors either for overall survival or disease recurrence.

We also correlated NO levels with other inflammation markers, with the stage of the disease, and even with chemotherapy, since the measurement was performed before and after three cycles of chemotherapy. The NO sensitivity marker is affected by both environmental and pharmaceutical factors, as well as by history of smoking.

Thus, the ultimate goal of the study was to demonstrate that NO is a risk factor for chronic inflammation of the respiratory system. ${ }^{25}$

\section{Materials and methods}

Forty-two newly-diagnosed patients (26 men and 16 women) with lung cancer were studied, irrespective of histological type. They were submitted to blood tests (complete blood count, erythrocyte sedimentation rate, C-reactive protein), full biochemistry analysis (urea, creatinine, total proteins, albumin, bilirubin, serum glutamic oxaloacetic transaminase, serum glutamic pyruvate transaminase, alkaline phosphatase, $\gamma$-glutamyl transpeptidase, $\mathrm{K}, \mathrm{Na}, \mathrm{Ca}$ ), full functional respiratory test, and alveolar exhaled NO test (Table 1). Patients were matched for as many common characteristics as possible, such as smoking history with the same number of packs per year, good-performance status (0-1), common geographical origin for environmental reasons (eg, coming from a large city, such as Athens or Thessaloniki), and withdrawal from 
any anti-inflammatory medication, eg, cortisone. Therefore, we avoided including in the study patients with brain and bone metastases receiving anti-inflammatory medication.

The patients were submitted to serum sampling to measure NO level, and a full functional respiratory test was performed upon diagnosis and after three cycles of chemotherapy. Also, patients who had undergone adjuvant chemotherapy were excluded, because it has been shown that surgical interventions increase inflammation markers, and this would lead to false conclusions.

Valuable information was recorded from the patients' medical files, such as the stage and the location of the disease, date of disease recurrence or progression, total length of survival, pathoanatomical features such as histological type, differentiation, and immunohistochemistry of the tumor, as well as clinical data such as possible weight loss through body mass index and skeletal mass index (SMI) measurement. In addition, potential chemotherapy side effects and growthfactor administration were recorded in order to obtain as much information as possible, so as to avoid any acute inflammation that would bias NO-related data (Table 2 and Table 3). The study was approved by the investigational review boards of Sotiria Hospital and G Papanikolaou General Hospital, and all patients signed an informed consent.

\section{Results}

All data were correlated with exhaled NO values. Statistical data analysis was performed with SPSS 17 (IBM, Armonk, NY, USA) software. Due to patient numbers, statistical analysis was conducted with nonparametric factors and the multifactorial study was confirmed by $t$-test and analysis of variance.

A decrease in exhaled NO was recorded after three cycles of chemotherapy in all patients, regardless of histology type and stage. More particularly, 42 patients with an original NO mean value of 9.8 presented a mean value of 7.7 after three cycles of chemotherapy. Also, a strong positive correlation appeared between $\mathrm{NO}$ before and after chemotherapy and $\mathrm{C}$-reactive protein $(P<0.05, r=0.42$ [before] and $P<0.045, r=0.64$ [after]). Another interesting strong positive correlation was recorded between exhaled NO and monocytes $(P<0.003, r=0.49)$, irrespective of chemotherapy, ie, both before and after chemotherapy. In contrast, although NO would be expected to correlate with eosinophils, this was not demonstrated in our study.

\section{Discussion}

In this study, there was a positive correlation of exhaled $\mathrm{NO}$ with one common inflammation marker and an evident
Table I Patient characteristics

\begin{tabular}{lll}
\hline & Mean values & \\
\cline { 2 - 3 } & Men & Women \\
\hline Number & 26 & 16 \\
Age (years) & $66.6 \pm 18$ & $62.4 \pm 15$ \\
Body mass index & $27.8 \pm 5$ & $25.6 \pm 4$ \\
FEV, (\%) & $75 \pm 12$ & $81 \pm 15$ \\
Smoking (pack-years) & $54 \pm 8$ & $45 \pm 6$ \\
\hline
\end{tabular}

Note: values are shown as mean \pm standard deviation.

Abbreviation: $\mathrm{FEV}_{1}$, forced expiratory volume in I second.

spontaneous decrease after three cycles of chemotherapy. However, it is also important to examine first the NO increase in patients with first-diagnosed primary lung cancer. According to studies by Chan et $\mathrm{al}^{26}$ and Wewel et al, ${ }^{27}$ the increase of oxidative stress that occurs during lung cancer oncogenesis affects exhaled NO through the reverse relation of $\mathrm{H}_{2} \mathrm{O}_{2}$ with atmospherically exhaled NO. This mechanism was first observed in atmospheric pollution in measurements that were performed and followed by further analyses. Therefore, NO measurement was conducted under the most strictly controlled conditions, because it is a measurement that is highly sensitive to exogenous factors.

The concurrent decrease of $\mathrm{NO}$ and monocytes and their high correlation is justified by the interpretation that the monocytes/macrophages are basically involved in the production of NO. Identical results from another study by Masri et al proved this to be true. Furthermore, in two studies, it seemed that monocytes and NO reached the nadir at the moment when the chemotherapy drug reached its peak activity. ${ }^{28,29}$

A basic parameter taken into account is the significant effect of smoking on the change of exhaled NO. It has also been observed that smoking needs to be given up for at least 6-8 weeks so that NO is restored to its normal levels. Thus, an initial mean value in the order of 6.8 may be justified, since patients from diagnosis to chemotherapy onset quit smoking, and this period is usually no longer than a month. It would have been valuable if we were able to examine the initial NO value during a longer time period. However, this was impossible due to the severity of the disease and the emergency treatment required. Furthermore, similar

Table 2 Histological classification

\begin{tabular}{ll}
\hline & Number of subjects \\
\hline Squamous & 12 \\
Adenocarcinoma & 18 \\
Small-cell carcinoma & 9 \\
Large-cell carcinoma & 2 \\
Combined & $\mathrm{I}$ \\
\hline
\end{tabular}


Table 3 Results before and after three chemotherapy cycles

\begin{tabular}{lcc}
\hline & Before & After \\
\hline NO & $9.8 \pm 2.1$ & $7.7 \pm 1.6$ \\
CRP & $1.7 \pm 0.3$ & $0.9 \pm 0.15$ \\
WBC & $7.6 \pm 2.1$ & $6.7 \pm 1.8$ \\
NEUT (\%) & $68 \pm 15$ & $71 \pm 16$ \\
LYMPH (\%) & $20 \pm 4$ & $21 \pm 6$ \\
MONO (\%) & $10 \pm 2$ & $7 \pm 1.5$ \\
\hline
\end{tabular}

Abbreviations: NO, nitric oxide; CRP, C reactive protein; WBC, white blood cell; NEUT, neutrophils; LYMPH, lymphocytes; MONO, monocytes.

results were observed in two more studies following local radiotherapy in lung cancer. Specifically, Inoue et al studied the behavior of NO in patients with lung cancer and observed a significant NO reduction, with the exception of patients who developed postradiation pneumonitis and had three- to fourfold higher NO levels. ${ }^{30,31}$

Finally, in studies performed on the basis of the size and count of macrophages in relation to $\mathrm{NO}$, a positive correlation was proven only with macrophages and exhaled NO. ${ }^{32}$ Also, in studies by Liu et a ${ }^{32}$ a correlation was observed between interleukin 4 and interferon- $\gamma$ and exhaled NO. These studies certainly refer only to the time of first lung cancer diagnosis and not following therapeutic treatments.

Consequently, in our study, which was performed at two time points (before and after chemotherapy), some previous studies have been confirmed, but nothing equivalent has been published yet.

\section{Conclusion}

$\mathrm{NO}$ as an airway-inflammation marker indicates response to lung cancer chemotherapy. Consequently, the inflammatory process in lung cancer is confirmed, but also shows response to chemotherapy through a marker that is sensitive to airway inflammatory diseases and has never been used before in the context of lung cancer before and after chemotherapy. A strong correlation with monocytes before and after treatment confirms the results, since we know that monocytes are involved in the production of NO.

\section{Disclosure}

The authors report no conflicts of interest in this work.

\section{References}

1. Samet JM, Albert AJ, Ford JG. Epidemiology of lung cancer and mesothelioma. Eur Respir Soc Monogr. 2009;44:349-391.

2. Jemal A, Siegel R, Ward E, Hao Y, Xu J, Thun MJ. Cancer statistics, 2009. CA Cancer J Clin. 2009;59:225-249.

3. Kontakiotis T, Manolakoglou N, Zoglopitis F, et al. Epidemiologic trends in lung cancer over two decades in Northern Greece: an analysis of bronchoscopic data. Monaldi Arch Chest Dis. 2009;71:147-152.
4. Wistuba II, Liao Z, Milas L. Molecular biology of lung cancer. In: Syrigos KN, Nutting CH, Roussos C, editors. Tumors of the Chest. Berlin: Springer; 2006.

5. Politi EN, Syrigos KN. Preneoplastic lesions of the lung. In: Syrigos KN, Nutting CH, Roussos C, editors. Tumors of the Chest. Berlin: Springer; 2006.

6. Chanin TD, Merrick DT, Franklin WA, Hirsch FR. Recent developments in biomarkers for the early detection of lung cancer: perspectives based on publications 2003 to present. Curr Opin Pulm Med. 2004;10: 242-247.

7. Barnes SD. Nitric oxide in acute respiratory distress syndrome: enhancing our knowledge at the bench. Crit Care Med. 1998;26:1157-1158.

8. Anggard E. Nitric oxide: mediator, murderer, and medicine. Lancet. 1994;343:1199-1206.

9. American Thoracic Society, European Respiratory Society. ATS/ERS recommendations for standardized procedures for the online and offline measurement of exhaled lower respiratory nitric oxide and nasal nitric oxide, 2005. Am J Respir Crit Care Med. 2005;171:912-930.

10. Barnes PJ. Transcription factors and inflammatory disease. Hosp Pract (1995). 1996;31(6):93-100, 105-106.

11. Beckmann J, Tsai J. Reactions and diffusion of nitric oxide and peroxynitrite. Biochemist. 1994;16:8-10.

12. Bel EH, Chanex P. Diagnosis and assessment of asthma. Eur Respir Soc Monogr. 2003:23.

13. Belvisi M, Barnes PJ, Larkin S, et al. Nitric oxide synthase activity is elevated in inflammatory lung disease in humans. Eur J Pharmacol. 1995;283:255-258.

14. Berkman N, Avital A, Breuer R, Bardach E, Springer C, Godfrey S. Exhaled nitric oxide in the diagnosis of asthma: comparison with bronchial provocation tests. Thorax. 2005;60:383-388.

15. Berlyne GS, Parameswaran K, Kamada D, Efthimiadis A, Hargreave FE. A comparison of exhaled nitric oxide and induced sputum as markers of airway inflammation. J Allergy Clin Immunol. 2000;106:638-644.

16. Horváth I, Donnelly LE, Kiss A, et al. Combined use of exhaled hydrogen peroxide and nitric oxide in monitoring asthma. Am J Respir Crit Care Med. 1998;158:1042-1046.

17. Horváth I, Donnelly LE, Kiss A, Paredi P, Kharitonov SA, Barnes PJ. Raised levels of exhaled carbon monoxide are associated with an increased expression of heme oxygenase- 1 in airway macrophages in asthma: a new marker of oxidative stress. Thorax. 1998;53: 668-672.

18. Horváth I, Hunt J, Barnes PJ, et al. Exhaled breath condensate: methodological recommendations and unresolved questions. Eur Respir J. 2005;26:523-548.

19. Horváth I, Loukides S, Wodehouse T, Kharitonov SA, Cole PJ, Barnes PJ. Increased levels of exhaled carbon monoxide in bronchiectasis: a new marker of oxidative stress. Thorax. 1998;53:867-870.

20. Hovárth I. Airway inflammation: exhaled NO measurement in clinical practice. Breathe. 2005;1:229-235.

21. Boucher RC. New concepts of the pathogenesis of cystic fibrosis lung disease. Eur Respir J. 2004;23:146-158.

22. Nightingale AK, James PP, Morris-Thurgood J, et al. Evidence against oxidative stress as mechanism of endothelial dysfunction in methionine loading model. Am J Physiol Heart Circ Physiol. 2001;280:H1334-H1339.

23. Misko TP, Schilling RJ, Salvemini D, Moore WM, Currie MG. A fluorometric assay for the measurement of nitrite in biological samples. Anal Biochem. 1993;214:11-16.

24. Salvemini D, Misko TP, Masferrer JL, Seibert K, Currie MG, Needleman P. Nitric oxide activates cyclooxygenase enzymes. Proc Natl Acad Sci U SA. 1993;90:7240-7244.

25. Barnes PJ, Chung KF, Page CP. Inflammatory mediators of asthma: an update. Pharmacol Rev. 1998;50:515-596.

26. Chan EY, Ng DK, Chan CH. Measuring FENO in asthma: coexisting allergic rhinitis and severity of atopy as confounding factors. $\mathrm{Am} \mathrm{J}$ Respir Crit Care Med. 2009;180:281; author reply 282. 
27. Wewel AR, Crusius JA, Gatzemeier U, et al. Time course of exhaled hydrogen peroxide and nitric oxide during chemotherapy. Eur Respir J. 2006;27:1033-1039.

28. Masri F. Role of nitric oxide and its metabolites as potential markers in lung cancer. Ann Thorac Med. 2010;5:123-127.

29. Masri FA, Comhair SA, Koeck T, et al. Abnormalities in nitric oxide and its derivatives in lung cancer. Am J Respir Crit Care Med. 2005;172: 597-605.

30. Inoue H, Sakurai S, Yamauchi K. Respiratory disorders and nitric oxide. Nihon Naika Gakkai Zasshi. 1997;86:1795-1799. Japanese.
31. Inoue A, Kunitoh H, Sekine I, Sumi M, Tokuuye K, Saijo N. Radiation pneumonitis in lung cancer patients: a retrospective study of risk factors and the long-term prognosis. Int J Radiat Oncol Biol Phys. 2001;49: 649-655.

32. Liu CY, Wang CH, Chen TC, Lin HC, Yu CT, Kuo HP. Increased level of exhaled nitric oxide and up-regulation of inducible nitric oxide synthase in patients with primary lung cancer. Br J Cancer. 1998;78: 534-541.

\section{Publish your work in this journal}

OncoTargets and Therapy is an international, peer-reviewed, open access journal focusing on the pathological basis of all cancers, potential targets for therapy and treatment protocols employed to improve the management of cancer patients. The journal also focuses on the impact of management programs and new therapeutic agents and protocols on

\section{Dovepress}

patient perspectives such as quality of life, adherence and satisfaction. The manuscript management system is completely online and includes a very quick and fair peer-review system, which is all easy to use. Visit http://www.dovepress.com/testimonials.php to read real quotes from published authors.

Submit your manuscript here: http://www.dovepress.com/oncotargets-and-therapy-journal 